\title{
Monitor the Processes of Ice Film Disappearance under a Stimulant Convection Condition and Absorption Ethanol Vapor to Ice by a Quartz Crystal Microbalance
}

\author{
Lei $\mathrm{Yu}^{1}$, Xiaolong $\mathrm{Ma}^{2}$, Ting $\mathrm{Wu}^{2}$,Yangyang $\mathrm{Ma}^{2}$, Dazhong Shen, Qi Kang ${ }^{2, *}$ \\ ${ }^{1}$ Department of Chemical Engineering and Environment, Weifang University of Science and \\ Technology, Weifang 262700, P. R. China. \\ ${ }^{2}$ College of Chemistry, Chemical Engineering and Materials Science, Collaborative Innovation Center \\ of Functionalized Probes for Chemical Imaging in Universities of Shandong, Key Laboratory of \\ Molecular and Nano Probes, Ministry of Education, Shandong Provincial Key Laboratory of Clean \\ Production of Fine Chemicals, Shandong Normal University, Jinan 250014, P. R. China. \\ *E-mail: qikang@sdu.edu.cn
}

doi: $10.20964 / 110402595$

Received: 24 January 2016 / Accepted: 19 February 2016 / Published: 1 March 2016

\begin{abstract}
In this work, the processes of ice film disappearance under a stimulant convection conditions and absorption to ethanol vapor to ice film were monitored by a quartz crystal microbalance (QCM) technique. The influence of the thickness of ice film on the response of the QCM was investigated by an impedance analysis method. It is shown that part of freshly prepared amorphous ice film on QCM is disappeared gradually during a stimulant convection process at $-18{ }^{\circ} \mathrm{C}$. We report a mulriple resonance phenomenon in QCM with unsymmetrical mass loading. The shape of the conductancefrequency spectrum of QCM depends on the thickness and distribution of the ice film deposited. After adsorption of ethanol vapor, the rigidity of the ice film is decreased gradually. With a large amount of ethanol adsorbed, the ice film is dissolved and evaporated completely. The QCM is a useful tool to monitor the mass and rigidity change of ice film.
\end{abstract}

Keywords: Quartz crystal microbalance; Unsymmetrical mass loading; Ice film; Adsorption

\section{FULL TEXT}

(C) 2016 The Authors. Published by ESG (www.electrochemsci.org). This article is an open access article distributed under the terms and conditions of the Creative Commons Attribution license (http://creativecommons.org/licenses/by/4.0/). 